\title{
PRINCÍPIOS DA ADMINISTRAÇÃO CIENTÍFICA: A REVOLUÇÃO DE TAYLOR
}

\section{Cláudio Filipe Lima Rapôso}

Mestrando em Administração na Universidad Columbia Del Paraguay - PY, Bacharel em Engenharia de Produção na Faculdade Estácio de Sá do Recife e Bacharelando em Engenharia Agrícola Ambiental na Universidade Federal Rural de Pernambuco.

\section{Marina Lourenço da Silva}

Bacharel em Arquitetura e Urbanismo na Universidade Federal de Pernambuco.

\section{AUTOR DA OBRA}

No dia 20 de março de 1856, Frederick Winslow Taylor nasceu na Pensilvânia (EUA), se formou em 1885 em Engenharia no Stevens Institute. Taylor era incansável na melhoria de produtividade diária de seus estimados empregados, logo se deu conta da miséria que aumentava as suas vidas.

Com 23 anos, pela primeira vez, aplicou os processos científicos. Em toda sua vida instigou-se sempre a introduzir em trabalhos próprios, sobre sua responsabilidade ou fiscalização métodos de observação e experimentação, com o objetivo de maximizar o rendimento do trabalho, quanto a melhora produtiva dos trabalhadores.

Como chefe de oficina, envolveu-se em mudanças no sistema de administrativo, com a finalidade de convergir às necessidades dos empregados e patrões, contrariando a tese antagônica.

A carreira dele foi bastante frenética, em um período de seis anos trabalhou de operário a engenheiro-chefe. 50 patentes de invenção sobre máquinas, ferramentas e processos de trabalho em seu nome. E pela sua grande contribuição a comunidade cientifica, desenvolveu a necessidade de melhoramento de processos.

\section{SÍNTESE DA OBRA}

Através de análises científicas, a obra expõe métodos que os operários deveriam utilizar para que o trabalho fosse feito da melhor maneira possível, introduzindo, assim, princípios científicos na administração.

0 autor evidencia, por meio de experimentos feitos sobre a tutela da Bethlehem Steel Company, logo no início de sua carreira. Com a experiência proveitosa, Taylor definiu os seguintes princípios básicos da observação ciêntifica: 
1. Atribuir a cada operário a tarefa mais elevada que lhe permitisse as aptidões.

2. Solicitar a cada operário o máximo de produção que se pudesse esperar de um trabalhador hábil de sua categoria.

3. Que cada operário, produzindo a maior soma de trabalho, tivesse uma remuneração adequada, ou seja, 30 a 50 por cento superior à média dos trabalhadores.

Posteriormente Taylor promoveu os seguintes objetivos:

1. Desenvolver uma ciência que pudesse aplicar-se a cada fase do trabalho humano, em lugar dos velhos métodos rotineiros.

2. Selecionar o melhor trabalhador para cada serviço, passando em seguida a ensinálo, treiná-lo e formá-lo, em lugar do antigo costume de deixar a ele que selecionasse o seu serviço e se formasse, da melhor maneira possível.

3. Criar um espírito de profunda cooperação entre a direção e os trabalhadores, com o objetivo de que as atividades se desenvolvessem de acordo com os princípios da ciência aperfeiçoada.

4. Dividir o trabalho de mesmos processos entre a direção e os trabalhadores, devendo cada departamento atuar sobre aqueles trabalhos para os quais estivesse mais bem preparado, substituindo dessa forma a antigas condições, nas quais quase todo o trabalho e a maior parte da responsabilidade recaíam sobre os empregados.

Como chefe de oficina, envolveu-se em mudanças no sistema de administrativo, com a finalidade de convergir às necessidades dos empregados e patrões, contrariando a tese antagônica.

Taylor em sua caminhada elaborou a lei da fadiga, instituída pelo autor, é exclusiva aos trabalhadores em que é atingido o limite da capacidade do homem pela fadiga. Taylor também afirma que sobre a seleção trabalhadora mais adequada sendo selecionado criteriosamente.

Dessa forma os resultados obtidos devem ser visivelmente superiores do que os utilizados no sistema por iniciativa e incentivos, medida bastante comum para o pagamento dos trabalhadores. 0 resultado sistema sobre os trabalhadores é a economia de dinheiro e uma vida melhor.

Na administração científica, outra contribuição de Taylor é os quatro grandes princípios fundamentais da administração:

1. Desenvolvimento de uma verdadeira ciência.

2. Seleção científica do trabalhador.

3. Sua instrução e treinamento científico.

4. Cooperação íntima e cordial entre a direção e os trabalhadores. 
Segundo o autor, a administração científica não um elemento simples, mas agregação das seguintes premissas:

\section{Ciência, em lugar de empirismo.}

\section{Harmonia, em vez de discórdia.}

\section{Cooperação, não individualismo.}

\section{Rendimento máximo, em lugar de produção reduzida.}

5. Desenvolvimento de cada homem, no sentido de alcançar maior eficiência $e$ prosperidade.

A utilização eventual da administração científica tende a potencializar linearmente a produtividade do trabalhador. Enquanto todo o mundo aproveita com este aumento de produção, o industrial e o operário verão crescer seus benefícios.

A administração científica, no contexto chefe e empregado, terá como resultado em longo prazo, aos que implantaram a pacificação nas disputas e desentendimentos entre os agentes citados.

Outro resultado é a melhoria na qualidade de vida e diminuição das diferenças sociais, não exclusivamente trabalhadores, mas também os stakeholders envolvidos.

Os trabalhadores são sistematicamente treinados para alcançar a maior eficiência e aprende a fazer espécie de trabalho superior, destacando-se dos antigos sistemas de gestão. Sua conduta será cordial para em relação aos chefes e o zelo pelas condições de trabalho.

\section{CONSIDERAÇÕES FINAIS}

As dificuldades eram evidentes na aplicação diárias dos conceitos científicos a operários sob suas ordens. Evidencia-se em diversos aspectos, problemas na implementação dos princípios científicos nas empresas em que foram aplicadas.

No contexto, a intermediação entre esses agentes era algo bastante difícil, e o consenso na prática diária é bastante trabalhoso. Dessa forma Taylor foi primordial para a melhoria dos rendimentos na empresas em que trabalhou.

Em toda sua trajetória, Taylor, através de seus estudos científicos, deixou um acervo de conhecimento inegável que possibilitou o melhoramento continuo da produtividade, e a satisfação de todos os agentes do Sistema Administrativo.

\section{REFERÊNCIA BIBLIOGRÁFICA}

- TAYLOR, Frederick Winslow. Princípios de Administração Científica. São Paulo: Atlas, 1966. 


\section{NOTAS BIOGRÁFICAS}

\section{Cláudio Filipe Lima Rapôso}

Mestrando em Administração (IDEIA/Columbia), Pós Graduado em Gestão em Engenharia de Produção (Instituto Graduarte), MBA em Gestão de Projetos (Instituto Graduarte), Bacharel em Engenharia de Produção (Faculdade Estácio de Sá do Recife) e Bacharelando em Engenharia Agrícola Ambiental (UFRPE). Participante das equipes Campus Party Recife (2012 à 2016), Palestrante sobre Gestão Industrial, Gestão da Qualidade, Gestão de Projetos, Gestão de Equipe e Empreendedorismo. Professor Autônomo de Excel Avançado, Microsoft Project e Primavera Project. Ex-Estagiário na empresa Petróleo Brasileiro S/A (PETROBRAS), Ex-Bolsista PIBIC no Laboratório Lasaq e Genoma (UFRPE) e CEO da Lourenço Raposo Consultoria MEI.

\section{Marina Lourenço da Silva}

Bacharel em Arquitetura e Urbanismo (UFPE). 